,pdfauthor=Sophie Groux-Degroote, Marie-Ange Krzewinski-Recchi, Aurélie Cazet, Audrey Vincent, Sylvain Lehoux, Jean-Jacques Lafitte, Isabelle van Seuningen, Philippe Delannoy,pdfkeywords=Life Sciences,pdfcreator $=$ HAL, pdfproducer $=$ PDFLaTeX,pdfsubject $=$ Life Sciences $[q-$ bio] $/$ Biochemistry, Molecular Biology
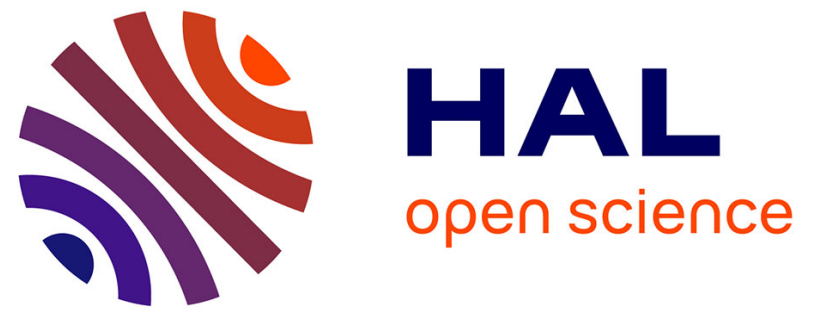

\title{
IL-6 and IL-8 increase the expression of glycosyltransferases and sulfotransferases involved in the biosynthesis of sialylated and/or sulfated Lewis x epitopes
} in the human bronchial mucosa

Sophie Groux-Degroote, Marie-Ange Krzewinski-Recchi, Aurélie Cazet, Audrey Vincent, Sylvain Lehoux, Jean-Jacques Lafitte, Isabelle van Seuningen, Philippe Delannoy

\section{To cite this version:}

Sophie Groux-Degroote, Marie-Ange Krzewinski-Recchi, Aurélie Cazet, Audrey Vincent, Sylvain Lehoux, et al.. IL-6 and IL-8 increase the expression of glycosyltransferases and sulfotransferases involved in the biosynthesis of sialylated and/or sulfated Lewis x epitopes in the human bronchial mucosa. Biochemical Journal, 2008, 410 (1), pp.213-223. 10.1042/BJ20070958 . hal-00478849

\section{HAL Id: hal-00478849 https://hal.science/hal-00478849}

Submitted on 30 Apr 2010

HAL is a multi-disciplinary open access archive for the deposit and dissemination of scientific research documents, whether they are published or not. The documents may come from teaching and research institutions in France or abroad, or from public or private research centers.
L'archive ouverte pluridisciplinaire HAL, est destinée au dépôt et à la diffusion de documents scientifiques de niveau recherche, publiés ou non, émanant des établissements d'enseignement et de recherche français ou étrangers, des laboratoires publics ou privés. 


\section{IL-6 and IL-8 increase the expression of Glycosyltransferases and Sulfotransferases involved in} the Biosynthesis of Sialylated and/or Sulfated Lewis ${ }^{\mathrm{x}}$ epitopes in the Human Bronchial Mucosa

Sophie Groux-Degroote ${ }^{*}$, Marie-Ange Krzewinski-Recchi ${ }^{*}$, Aurélie Cazet ${ }^{*}$, Audrey Vincent ${ }^{\dagger}$, Sylvain Lehoux $^{*}$, Jean-Jacques Lafitte ${ }^{\ddagger}$, Isabelle van Seuningen ${ }^{\dagger}$, and Philippe Delannoy*

* Structural and Functional Glycobiology Unit, UMR CNRS 8576, University of Sciences and Technologies of Lille, France.

${ }^{\dagger}$ Inserm, U837, Centre de Recherche Jean-Pierre Aubert, Lille, F59045, France

* Calmette Hospital, Pneumophtisiology Laboratory, CHRU of Lille, France.

Correspondence should be addressed to Sophie Groux-Degroote, at Unité de Glycobiologie Structurale et Fonctionnelle, UMR CNRS n8576, Bâtiment C9, Université des Sciences et Technologies de Lille, F-59655 Villeneuve d'Ascq, France. Tel +33 3204369 23; Fax +33 3204365 55; E-mail: Sophie.Groux-Degroote@univ-lille1.fr

Page heading title: Terminal Glycosylation in Human Bronchial Mucosa. 


\section{SYNOPSIS}

Bronchial mucins from patients suffering from cystic fibrosis exhibit glycosylation alterations, espe-

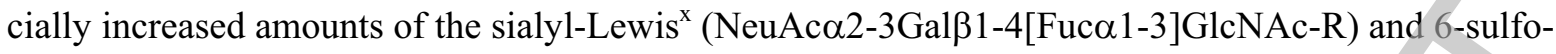
sialyl-Lewis ${ }^{\mathrm{x}}$ (NeuAc $\alpha 2-3 \mathrm{Gal} \beta 1-4[\mathrm{Fuc} \alpha 1-3]\left[\mathrm{SO}_{3} \mathrm{H}-6\right] \mathrm{GlcNAc}-\mathrm{R}$ ) terminal structures. These epitopes are preferential receptors for $P$. aeruginosa, the bacteria responsible for the chronicity of airway infection and involved in the morbidity and early death of cystic fibrosis patients. However, these glycosylation changes cannot be directly linked to defects in Cystic Fibrosis Transmembrane conductance Regulator gene expression since cells that secrete airway mucins express no or very low amounts of the protein. Several studies have shown that inflammation may affect glycosylation and sulfation of various glycoproteins, including mucins. In the present study, we show that incubations of macroscopically healthy fragments of human bronchial mucosa with interleukin 6 or 8 result in a significant increase of the expression of $\alpha 1,3 / 4$-fucosyltransferases (FUT11 and FUT3), $\alpha 2-6-$ and $\alpha 2,3-$ sialyltransferases (ST3GAL6 and ST6GAL2), and GlcNAc-6-O-sulfotransferases (CHST4 and CHST6) mRNA. In parallel, the amounts of sialyl-Lewis ${ }^{\mathrm{x}}$ and 6-sulfo-sialyl-Lewis ${ }^{\mathrm{x}}$ epitopes at the periphery of high molecular weight proteins, including MUC4, was also increased. In conclusion, our results indicate that interleukin 6 and 8 may contribute to the increased levels of sialyl-Lewis ${ }^{\mathrm{x}}$ and 6-sulfo-sialylLewis ${ }^{\mathrm{x}}$ epitopes on human airway mucins from patients with cystic fibrosis.

Key words: Mucin / glycosylation / Inflammation / Cystic Fibrosis / Real-Time PCR.

\section{INTRODUCTION}

Human bronchial mucins consist of a family of polydisperse glycoproteins of high molecular weight, with different polypeptide chains (named apomucins) substituted by carbohydrate chains in serine and threonine rich tandem repeats that are responsible for about 70 to $80 \%$ of their apparent molecular weight [1]. Apomucins of bronchial mucins are encoded by at least eight mucin (MUC) genes (MUC1, MUC2, MUC4, MUC5B, MUC5AC, MUC7, MUC8, and the recently characterized MUC19) [2]. Carbohydrate chains that cover the apomucins are extremely diverse, adding to the complexity of these molecules. Currently, more than 150 different $O$-linked carbohydrate chains have been described, and it is assumed that the bronchial mucins from a single individual probably contain a few hundred different carbohydrate chains [3]. In addition, because bronchial mucins are located at the surface of airways, where they have a protective function, the broad diversity of their carbohydrate peripheral determinants could be involved in multiple interactions with bacteria and viruses, which are then normally eliminated by the mucociliary system.

The biosynthesis of $O$-linked carbohydrate chains is a stepwise process involving number of glycosyland sulfotransferases. The only structural element shared by all mucin $O$-glycan chains is an $N$ acetylgalactosamine residue $\alpha$-linked to a serine or threonine residue of the apomucin. The nonreducing end of carbohydrate chains, which corresponds to the termination of the biosynthetic proc- 
ess, may bear different structures, such as blood groups A, B, or O determinants; $\mathrm{H}$ and sulfated $\mathrm{H}$ determinants; Lewis ${ }^{\mathrm{a}}$, Lewis ${ }^{\mathrm{b}}$, Lewis ${ }^{\mathrm{y}}$, or various derivatives of the Lewis ${ }^{\mathrm{x}}$ epitope, such as the sialylLewis $^{\mathrm{x}}, 3$-sulfo-Lewis ${ }^{\mathrm{x}}$, and 6-sulfo-sialyl-Lewis ${ }^{\mathrm{x}}$ determinants. The synthesis of these different terminal determinants involves different pathways utilizing a variety of transferases such as (i) $\alpha 2,3-$ sialyltransferases (encoded by $S T 3 G A L$ genes),,(ii) $\alpha 1,3$-fucosyltransferases (FUT), (iii) galactose-3$O$-sulfotransferases (GAL3ST), and (iv) $N$-acetylglucosamine-6-O-sulfotransferases (CHST) [4]. In the lung, it is not very clear yet which fucosyl-, sialyl-, and sulfotransferases are involved in the biosynthesis of these determinants that are present at the periphery of mucins and probably crucial in many pathologies, including cystic fibrosis.

Inflammation plays a major role in the pathophysiology of lung disease in cystic fibrosis $\left(\mathrm{CF}^{1}\right)$ : the inflammatory response is thought to be abnormal and/or excessive in cystic fibrosis, which would contribute to the degradation of the respiratory function of the patients. It is still a matter of debate whether there may or may not be a pre-inflammation of the lungs as part of the basic functional defect of the cystic fibrosis transmembrane conductance regulator (CFTR). Armstrong and colleagues [5] have suggested that inflammation may even precede infection in this disease. The presence of increased neutrophils and cytokines such as tumour necrosis factor $\alpha$ (TNF $\alpha$ ), interleukins (IL) -6 and 8 in young infants with cystic fibrosis with no evidence of infection has also been shown [6-7]. There is also accumulating evidence that the secretion of several cytokines, especially IL-8, is up-regulated in CF [8]. In contrast, bronchoalveolar lavages from cystic fibrosis patients contain less anti-

inflammatory cytokine IL-10 than healthy controls and bronchial epithelial CF cells secrete less IL-10 than normal cells, suggesting that there could be an imbalance between pro- and anti-inflammatory cytokines in cystic fibrosis, leading to an exaggerated inflammatory response that would be at the onset of the lung disease and/or would contribute to the lung disease development [9-10].

Glycosylation defects on glycoconjugates secreted by CF patients or present on the membrane of CF cells have been described since the 70's. Bronchial mucins secreted by CF patients are more sulfated, sialylated and fucosylated, and salivary and intestinal mucins from CF patients also contain more sulfate than healthy individuals [11-13]. In addition, it has been shown the sialyl-Lewis ${ }^{\mathrm{x}}$ epitope is overexpressed on bronchial mucins from severely infected CF patients, but also on bronchial mucins from infected patients suffering from other lung pathologies [14]. [ $\left.{ }^{1} \mathrm{H}\right]$-NMR and mass spectroscopy have been used to determine the structures of oligosaccharides in bronchial mucins from CF and non-CF

\footnotetext{
${ }^{1}$ Abbreviations

CF: cystic fibrosis; CFTR: cystic fibrosis transmembrane conductance regulator; $C H S T$ : carbohydrate sulfotransferase gene; Fuc: fucose; FUT: fucosyltransferase gene; IL: interleukin; GlcNAc: $N$ acetylglucosamine; GAL3ST: Gal-3-O-sulfotransferase gene; GlcNAc6ST: GlcNAc-6-O-

sulfotransferase; mAb: monoclonal antibody; $M U C$ : mucin gene; PBS: phosphate buffer saline; SDSPAGE: sodium dodecyl sulfate polyacrylamide gel electrophoresis; $S T 6 G A L$-: $\alpha 2,6$-sialyltransferase gene; ST3GAL: $\alpha 2,3$-sialyltransferase gene; TBS: Tris Buffer Saline; TNF: tumor necrosis factor.
} 
patients, which confirmed the increased presence of sialyl-Lewis ${ }^{\mathrm{x}}$ epitopes and $\mathrm{HO}_{3} \mathrm{~S}-6-\mathrm{N}-$ acetylglucosamine (GlcNAc) residues [15].

Interestingly, it seems that glycosylation of secreted and membrane glycoconjugates is either not affected by the level of expression of CFTR [16-17] or that membrane bound CF glycoconjugates are differently affected than secreted glycoconjugates. CF membrane glycoconjugates show a decreased sialylation compared with non-CF [18] whereas mucins secreted by $\mathrm{CF}$ patients are oversialylated. These discrepancies suggest that other factors than the CFTR deficiency could be responsible for the altered glycosylation and sulfation of CF mucins. It is of particular interest to understand the origin of the sialylation, fucosylation and sulfation modifications carried by CF bronchial mucins, because the sialyl-Lewis ${ }^{\mathrm{x}}$ and 6-sulfo-sialyl-Lewis ${ }^{\mathrm{x}}$ epitopes that are overexpressed on these mucins are preferential receptors for $P$. aeruginosa, the bacteria responsible for the progressive destruction of CF patients lungs [19]. As already mentioned, it has been shown that inflammation could induce modifications of glycosylation in the lung, such as an overexpression of the sialyl-Lewis epitope on bronchial mucins [14]. In addition, the pro-inflammatory cytokine TNF $\alpha$ can induce increased expression and activities of some sialyl-, fucosyl-, and sulfotransferases in human bronchial explants as well as in the human respiratory glandular cell line (MM-39) [20]. IL-6 and IL-8 are present in high amount in bronchoalveolar fluids from $\mathrm{CF}$, but their effect on glycosylation is still unknown.

In the present study, we have investigated the effect of these two cytokines on the expression and activity of bronchial glycosyl- and sulfotransferases. We show an increased expression of several fucosyl-, sialyl- and sulfotransferases, as well as increased amounts of sialyl-Lewis ${ }^{\mathrm{x}}$ and 6-sulfo-sialylLewis ${ }^{\mathrm{x}}$ epitopes on bronchial proteins, including MUC4, which could influence the development of the lung pathology.

\section{EXPERIMENTAL}

\section{Materials}

The monoclonal antibodies (mAb) against the sialyl-Lewis ${ }^{\mathrm{x}}$ (CSLEX1)and 6-sulfo-sialyl-Lewis ${ }^{\mathrm{x}}$ (G152) epitopes were from BD Pharmingen (San Diego, California, United States) and a kind gift from R. Kannagi (Aichi Cancer Center, Nagoya, Japan), respectively. HRP-labelled goat anti-mouse IgG secondary antibodies were from Amersham Biosciences (Uppsala, Sweden). Cytokines IL-6 and IL-8 were from AbCys S.A. (France). Culture media were from Invitrogen (Paisley, UK). Alkaline phosphatase conjugated Maackia amurensis agglutinin (MAA) and Sambucus nigra agglutinin (SNA) were from E.Y. Laboratories Inc. (San Mateo, CA, USA). Clostridium perfringens sialidase was from Sigma.

\section{Explants Culture}

In accordance with the Declaration of Helsinki (2000) of the World Medical Association, after ethical committee approval (CHRU Lille) and informed consent from patients had been obtained, tissues 
were collected in macroscopically healthy areas of the bronchial tree from patients undergoing surgery for bronchial carcinoma. They were immersed in Leibovitz L15 medium (Invitrogen), immediately transported on ice to the laboratory, and then processed to isolate the mucosa. Mucosa $\left(1-2 \mathrm{~cm}^{2}\right)$ were cut into $1-\mathrm{mm}^{2}$ pieces and suspended in CMRL-1066 medium (Invitrogen) complemented with $0.2 \mathrm{mM}$ L-glutamine [4]. They were maintained at $37^{\circ} \mathrm{C}$ for $16 \mathrm{~h}$ in the presence or absence (controls) of $20 \mathrm{ng} / \mathrm{ml}$ IL-6 or IL-8 (AbCys S.A., France).

\section{RNA Isolation and cDNA Synthesis}

Total RNA was isolated from fragments of bronchial mucosa incubated with and without IL-6 or IL-8 for $16 \mathrm{~h}$, using the NucleoSpin ${ }^{\circledR}$ RNA II (Macherey-Nagel). Isolated RNA (1-2 $\mu \mathrm{g}$ ) was then subjected to reverse transcription in the presence of oligodeoxythymidilic acid $12-18$ primer (First strand cDNA synthesis kit, Amersham Biosciences) for cDNA synthesis in a final volume of $33 \mu \mathrm{l}$ according to the manufacturer's instructions.

\section{Semi-quantitative and quantitative PCR Analysis of Mucin, Glycosyltransferase and Sulfotrans-} ferase Transcriptional Expression

The oligonucleotides used as primers for the PCR reactions are given in Tables I and II (available online as supplementary data). They were obtained from Eurogentec (Belgium) and some of them have been described previously. The expression of fucosyltransferase (FUT1 to FUT7, FUT9 to FUT11), sialyl- (ST3GAL3, 4, 6; ST6GAL1 and 2), sulfotransferase- (GAL3ST2 to 4 and CHST2, 4, 6, I-GlcNAc6ST) and mucin (MUC4, 5AC, 5B, 6) genes was first studied in control and treated explants by end-point PCR, using an appropriate positive control. For each end-point PCR reaction, amplifications were performed using $2 \mu \mathrm{l}$ of total cDNA from control or treated explants in a final volume of $50 \mu$ l, using the PCR mix Taq \& Go ${ }^{\mathrm{TM}}$ Mastermix (Q-BIOgene, final composition Tris-HCl $10 \mathrm{mM}$, pH 9.0, KCl 50 mM, $\mathrm{MgCl}_{2} 1.5 \mathrm{mM}$, Triton X-100 0.1 \%, BSA $0.2 \mathrm{mg} / \mathrm{ml}$, dNTP $100 \mu \mathrm{M}$ each, Taq DNA polymerase $0.02 \mathrm{U} / \mu \mathrm{l}$, glycerol $2 \%$ ), and $150 \mu \mathrm{M}$ of sense and antisense primers. When primers were from a previous study, the amplification conditions were according to the author's instructions (see Tables 1 and 2 for references). For primers designed for this study, the amplification conditions were the following: $95^{\circ} \mathrm{C}$ for $2 \mathrm{~min}, 1$ cycle; $95^{\circ} \mathrm{C}$ for $1 \mathrm{~min}$, Ta (Annealing temperature, see Table I) for $1 \mathrm{~min}, 72^{\circ} \mathrm{C}$ for $1 \mathrm{~min}, 39 \mathrm{cycles}, 72^{\circ} \mathrm{C}$ for $5 \mathrm{~min}, 1$ cycle. Twenty microliters of the PCR reaction were submitted to electrophoresis on an agarose gel (2\% in a Tris Borate EDTA buffer) containing ethidium bromide. Gels were photographed under UV light, and the expression of the different enzymes was analyzed. This first step allowed us to select the genes expressed in control or treated human bronchial explants.

Variations in the enzyme mRNA levels present in control or treated bronchial explants were then quantified by real-time PCR. Real-time PCR and subsequent data analysis were performed using the 
Mx4000 Multiplex Quantitative PCR System (Stratagene, La Jolla, CA, USA) equipped with Version 3.0 software. Each $25 \mu 1$ PCR reaction contained $12.5 \mu$ of the $2 X$ Brilliant ${ }^{\circledR} \operatorname{SYBR}^{\circledR}$ Green QPCR master mix (Stratagene), $300 \mathrm{nM}$ of each primer, and $2 \mu 1$ of cDNA diluted to $1 / 20$. DNA amplification was performed with the following thermal cycling profile: initial denaturation at $94^{\circ} \mathrm{C}$ for $10 \mathrm{~min}$, 40 cycles of amplification (denaturation at $94^{\circ} \mathrm{C}$ for $30 \mathrm{~s}$, annealing at $\mathrm{Ta}$ (Ta depending on the glycosyltransferase or mucin gene of interest, see Tables 1 and 2) for $30 \mathrm{~s}$, and extension at $72^{\circ} \mathrm{C}$ for $45 \mathrm{~s}$ ), and a final extension at $72{ }^{\circ} \mathrm{C}$ for $5 \mathrm{~min}$. The fluorescence monitoring occurred at the end of each cycle. The analysis of amplification results was performed using the Mx4000 3.0 software. Cycle threshold $\left(\mathrm{C}_{\mathrm{T}}\right)$ is defined as the number of PCR cycles where the fluorescence signal exceeds the detection threshold value. The amplification efficiencies were determined by serial dilution of cDNA synthesis products from a pool of total RNA extracted from bronchial explants, or from different cell lines (HT-29, HepG2, Hela, leukocytes), and were found in a range 97/110\%. The specificity of the amplification was checked by recording the dissociation curves after each run, and visualizing the amplified products by $2 \%$ agarose gel electrophoresis in the presence of ethidium bromide. RPLPO (acidic ribosomal phosphoprotein P0) was used as a control gene to normalize the expression of our genes of interest. To determine the relative amount of the different glycosyl- and sulfotransferases in the treated explants versus the controls, we first checked the efficiency of the amplifications by making standard curves using serial dilutions of cDNA from bronchial explants or an appropriate cell line when the expression was too low in the explants. The representation of $\mathrm{Ct}=\mathrm{ax} \log$ (initial quantity) + $\mathrm{b}$, allowed us to determine the efficiency of the reactions, and to use the $\mathrm{Ct}$ obtained in our studies to determine the quantity of transcripts of the different glycosyl- and sulfotransferases.

\section{Statistical Analysis}

Variations in mRNA levels of glycosyltransferases were calculated on 6 individual mucosae treated or not with IL-6 or IL-8 $(20 \mathrm{ng} / \mathrm{ml}, 16 \mathrm{~h})$. The Student's $t$ test was used to compare the means of the relative amount of each glycosyl- or sulfotransferase between the groups of treated and control explants. Statistical significance for this analysis was considered at $\mathrm{p}<0.05$.

\section{Preparation of total proteins from bronchial explants}

After $16 \mathrm{~h}$ incubation in CMRL-1066 +/- $20 \mathrm{ng} / \mathrm{ml}$ of IL-6 or IL-8, pieces of mucosa were collected and centrifuged at $10000 \times \mathrm{g}$ for $5 \mathrm{~min}$ at $4{ }^{\circ} \mathrm{C}$, and then rinsed two times with ice cold phosphate buffer saline (PBS). Pieces of mucosa were then disintegrated on ice with a glass homogenizer, in a modified RIPA buffer ( $150 \mathrm{mM}$ sodium chloride, $50 \mathrm{mM}$ Tris-HCl, $\mathrm{pH}$ 7.4, containing $1 \mathrm{mM}$ ethylenediaminetetracetic acid, $1 \mathrm{mM}$ phenylmethylsulfonylfluoride, 1 \% Triton X-100, 1 \% sodium deoxycholic acid, and a cocktail of protease inhibitors (Roche)). Protein extracts were then centrifuged at $10000 \times \mathrm{g}$ for $5 \mathrm{~min}$ at $4{ }^{\circ} \mathrm{C}$ to get rid of non-homogenized tissue. The concentration of super- 
natants was determined with the "Micro BCA ${ }^{\mathrm{TM}}$ Protein Assay Reagent Kit" (Pierce). The lysates were then stored at $-80^{\circ} \mathrm{C}$ and subsequently used for immunoblotting analysis.

\section{Immunoblotting analysis of bronchial proteins for sialyl-Lewis ${ }^{\mathrm{x}}$ and 6-sulfo-sialyl-Lewis ${ }^{\mathrm{x}}$ deter- minants}

Total proteins $(50 \mu \mathrm{g})$ from explants treated or not with IL-6 or IL-8 $(\mathrm{n}=5)$ were boiled for $5 \mathrm{~min}$ in reducing Laemmli sample buffer and resolved by sodium dodecyl sulfate polyacrylamide gel electrophoresis (SDS-PAGE) on 3-10\% gels $(15 \mathrm{~cm} \mathrm{x} 20 \mathrm{~cm})$. After transfer on nitrocellulose membrane $(250 \mathrm{~mA}, 5 \mathrm{~h})$, blocking was performed in Tris buffer Saline (TBS) $+0.05 \%$ Tween- $20+5 \%$ non fat dry milk for $90 \mathrm{~min}$. Part of the membrane was treated with Clostridium perfringens sialidase for $16 \mathrm{~h}$ at $37^{\circ} \mathrm{C}$ as a control for the specificity of the antibodies. Primary antibody incubations with anti-sialyl Lewis $^{\mathrm{x}}$ (clone CSLEX1, BD Pharmingen) or anti-6-sulfo sialyl Lewis ${ }^{\mathrm{x}}$ (G152, kind gift from R. Kannagi; [21]) antibodies were performed overnight at $4{ }^{\circ} \mathrm{C}$ in PBS, $5 \%$ milk, $0.05 \%$ Tween-20, at 1:500 dilution for CSLEX1 or at 1:20 dilution for G152. After 3 washing steps of $10 \mathrm{~min}$ in TBS, $5 \%$ milk, $0.05 \%$ Tween-20, incubation for $1 \mathrm{~h}$ at room temperature with horseradish peroxydase-conjugated goat anti-mouse IgG was performed (dilution 1:3000 in TBS, $5 \%$ milk, $0.05 \%$ Tween-20). Membranes were finally washed 3 times for $5 \mathrm{~min}$ in TBS, $0.05 \%$ Tween-20 and twice in TBS, and detection was achieved using enhanced chemioluminescence (ECL Western blotting detection reagents, Amersham Biosciences, Little Chalfont, United Kingdom). MUC4 mucin detection in explants was carried out as previously described using a $1 \mu \mathrm{g} / \mathrm{ml}$ dilution of the antibody m8G7 [22].

\section{Lectin blotting analysis}

Sample preparation and electrophoresis were conducted as described above. After transfer on nitrocellulose membrane $(250 \mathrm{~mA}, 5 \mathrm{~h})$, blocking was performed in TBS containing $2 \%$ polyvinylpyrrolidone for $90 \mathrm{~min}$, followed by incubation with alkaline phosphatase conjugated MAA or alkaline phosphatase conjugated SNA, lectins that recognizes preferentially $\alpha 2,3$-linked or $\alpha 2,6$-linked sialic acid residues, respectively (dilution 1;75 in TBS containing $1 \mathrm{mM} \mathrm{MgCl}_{2}, 1 \mathrm{mM} \mathrm{MnCl} 2,1 \mathrm{mM} \mathrm{CaCl}_{2}, \mathrm{pH}$ 7.5) for $90 \mathrm{~min}$. After two washing steps of $10 \mathrm{~min}$ in TBS, detection was achieved using NBT/BCIP (Nitro-Blue Tetrazolium Chloride / 5-Bromo-4-Chloro-3'-Indolyphosphate p-Toluidine Salt) diluted 1:50 in Tris- $\mathrm{HCl} 0.1 \mathrm{M}, \mathrm{pH} 9.5$, containing $0.1 \mathrm{M} \mathrm{NaCl}$ and $0.05 \mathrm{M} \mathrm{MgCl}_{2}$.

\section{RESULTS}

Effect of IL-6 and IL-8 on the expression of sialyl-Lewis ${ }^{\mathrm{x}}$ and 6-sulfo-sialyl-Lewis ${ }^{\mathrm{x}}$ epitopes on proteins from bronchial explants.

In order to determine whether pro-inflammatory IL-6 or IL-8 could participate in the remodelling of the glycosylation pattern of respiratory mucins and increase sulfation and sialylation of Lewis ${ }^{\mathrm{x}}$ epi- 
topes in CF patients, total proteins extracted from bronchial explants, treated or not with IL-6 or IL-8 were analyzed by Western blotting. Samples from bronchial mucosa from 5 independent individuals were used to test the effect of both cytokines. $\alpha 2,3-$ and $\alpha 2,6$-sialylation were analyzed using MAA and SNA lectins, respectively, and sialyl-Lewis ${ }^{\mathrm{x}}$ and 6-sulfo-sialyl-Lewis ${ }^{\mathrm{x}}$ by immunoblotting using specific mAbs. Staining with MAA and SNA, lectins that recognize preferentially $\alpha 2,3-$ or $\alpha 2,6-$ linked sialic acid residues, respectively, was not modified in bronchial samples treated with either IL6 or IL-8 (Figure 1), suggesting that there was no overall increase in $\alpha 2-3$ - or $\alpha 2-6$-sialylation after cytokine treatment. In parallel, the binding of anti-sialyl-Lewis ${ }^{\mathrm{x}} \mathrm{mAb}$ was increased after IL-6 or IL-8 treatment. Data from two representative patients are shown on Figure 2A. In all samples, the antisialyl-Lewis ${ }^{\mathrm{x}} \mathrm{mAb}$ labelled proteins of high molecular weight (above $170 \mathrm{kDa}$ ). The intensity of the staining was variable between the different control samples, and the number of bands was between 1 and 3, all of high molecular weight and with a diffuse pattern, suggesting that they could correspond to mucins. Strikingly, in all samples containing proteins from explants stimulated by IL-6, the intensity of the signal increased (left panel, explants 1 and 2). The same result was observed for the explants treated by IL-8 (right panel, explants 3 and 4).

Results obtained with the anti-6-sulfo-sialyl-Lewis ${ }^{\mathrm{x}}$ antibody are shown on Figure 2B (data are shown for two representative patients). In control explants, the anti-6-sulfo-sialyl-Lewis ${ }^{\mathrm{x}}$ antibody recognized only one band of high molecular weight (Figure 2B). The intensity of the staining for 6-sulfosialyl-Lewis ${ }^{\mathrm{x}}$ epitope was strongly increased in explants treated by IL-6 or IL-8, showing that bronchial explants treated with IL- 6 or IL-8 contained increased amount of this epitope.

These data suggest that IL- 6 or IL-8 did not deeply modified the overall sialylation pattern of bronchial mucosa but only increased the expression of specific glycan motifs, such as sialyl-Lewis ${ }^{\mathrm{x}}$ and 6sulfo-sialyl-Lewis ${ }^{\mathrm{x}}$.

\section{Identification of proteins carrying the 6-sulfo-sialyl-Lewis ${ }^{x}$ epitope}

Immunoblotting experiments suggest that proteins that carry sialyl-Lewis ${ }^{\mathrm{x}}$ and 6-sulfo-sialyl-Lewis ${ }^{\mathrm{x}}$ epitopes in bronchial explants could correspond to mucins, because of their high apparent molecular weight and diffuse migration pattern. In order to test this hypothesis, we quantatively determined using real-time PCR the level of mucin gene expression in the bronchial mucosa and checked whether their expression was modified by cytokine treatment. In all samples, $M U C 4$ was more expressed than $M U C 5 B$, which was more expressed than MUC5AC in most of the patients (Figure 3). MUC6 was expressed at very low levels $(\mathrm{Ct}>35)$ in bronchial explants and therefore could not be accurately quantified. The effect of IL-6 or IL-8 on the expression of MUC4, MUC5AC, and MUC5B in bronchial explants was then investigated and quantified using real-time PCR. Our results clearly showed that there was no consistent effect of these cytokines on the expression of MUC4, MUC5AC, and MUC5B mRNA in human bronchial explants. Important inter-individual variations in the level of transcripts 
were observed in control conditions and the effect of IL-6 and IL-8 was extremely variable between samples, with sometimes a stimulatory effect, or an inhibitory effect, or no effect at all (data not shown). These results indicate that the increase in sialyl-Lewis ${ }^{\mathrm{x}}$ and 6-sulfo-sialyl-Lewis ${ }^{\mathrm{x}}$ epitopes can not be directly linked to increased expression of mucin genes. The presence of mucins in the bronchial samples was also analyzed in total protein extracts from bronchial explants. Immunoblotting experiments showed a high expression of MUC4 in bronchial protein extracts. MUC1 and MUC5B were also detected but at a lower level compared to MUC4, and MUC5AC was not detected, confirming the results of real-time PCR analysis (data not shown, and Fig. 3). Moreover, the band of high molecular weight visualized using the 6-sulfo-sialyl-Lewis ${ }^{\mathrm{x}}$ antibody was in most cases also stained with the anti-MUC4 antibody (Figure 4), but not with anti-MUC5B or anti-MUC1 mAbs (data not shown), suggesting that MUC4 is the main protein carrying 6-sulfo-sialyl-Lewis ${ }^{\mathrm{x}}$ epitopes in the human bronchial mucosa.

\section{Effect of IL-6 and IL-8 on the transcriptional expression of sialyl-, fucosyl- and sulfotrans- ferases from bronchial explants.}

In order to determine which enzymes are responsible for the increased amounts of sialyl-Lewis ${ }^{\mathrm{x}}$ and 6-sulfo-sialyl-Lewis ${ }^{\mathrm{x}}$ found on human bronchial proteins in IL-6 or IL-8 treated explants, we first made a survey of fucosyl-, sialyl- and sulfotransferases expressed in human bronchial explants. We analyzed the expression of enzymes potentially involved in the biosynthesis of sialyl-Lewis ${ }^{\mathrm{x}}$ and 6sulfo-sialyl-Lewis ${ }^{\mathrm{x}}$ epitopes, i.e. $\alpha 1,3 / 4$-fucosyltransferases (FUT3 to 7 and FUT9 to 11), $\alpha 2,3$ sialyltransferases (ST3GAL1 to 4 and ST3GALO) and GlcNAc-6-O-sulfotransferases (CHST 2, CHST 4, CHST 6 and I-GlcNAc6ST). In addition, because human bronchial mucins were shown to contain Gal $\beta 1-4 G l c N A c$ disaccharide units substituted with $\alpha 1,2$-linked fucose (Fuc) residues, $\alpha 2,6$-linked sialic acid residues, or sulfate on the $\mathrm{C}_{3}$ of the Gal, we also investigated the expression of $\alpha 1,2-$ fucosyltransferases (FUT1 and FUT2), $\alpha 2,6$-sialyltransferases (ST6GAL1 and ST6GAL2) and Gal-3O-sulfotransferases (GAL3ST2, GAL3ST3 and GAL3ST4). After screening by end-point PCR, the expression of enzymes that were detected in control or treated explants was then analysed by real-time PCR. Our results indicate that ST6GAL1 was more expressed than ST6GAL2 in all control bronchial samples (in average 40-fold more) and that the expression of $S T 6 G A L 1$ was not affected by the addition of cytokines, whereas the expression of ST6GAL2 was highly stimulated by IL-6 or IL-8, with 5.7-46 fold or 5-11.8 fold increases, respectively (Figure 5A and B).. Among the ST3GAL genes studied, ST3GALA was the most expressed gene in bronchial explants (the ratio of absolute expression levels of ST3GAL4/ST3GAL3 and ST3GAL4/ST3GAL6 are 6.3 and 10.8, respectively). No significant variations in the transcriptional expression of $\alpha 2,3$-sialyltransferases ST3GAL3 and ST3GAL4 was observed when IL-6 or IL-8 was added, whereas the addition of IL- 6 significantly increased the expression of ST3GAL6 in all the bronchial explants tested (Figure 5A). Among the FUT genes studied, 
FUT1, FUT4, FUT5, FUT6, FUT7, and FUT9 were not expressed in the bronchial explants (control or treated with cytokines). In average, FUT10 was the most expressed fucosyltransferase gene in the control bronchial explants (FUT10/FUT3 and FUT10/FUT11 ratio are 2.5 and 4.2, respectively). Only FUT3 (encoding the Lewis $\alpha 1,3 / 4$-fucosyltransferase) showed an increased expression after IL-8 treatment, whereas the expression of FUT11 (encoding a potential fucosyltransferase of still unknown specificity) was moderately but significantly increased in the different explants tested (Figure 5A and B). GAL3ST2 and GAL3ST3 genes encoding Gal-3-O-sulfotransferases were not expressed at quantifiable levels in the bronchial explants, and the expression of GAL3ST4 was not significantly affected by the addition of IL-6 or IL-8 (Figure 5). Among the GlcNAc-6-O-sulfotransferase encoding genes, only CHST4 and CHST6 were expressed in our model, with CHST6 in average expressed 2.8-fold more than CHST4. Both enzymes had their expression increased under IL-6 treatment, whereas IL-8 had only a significant stimulatory effect on CHST6 expression (Figure 5). Altogether, these results identify the glycosyl- and sulfotransferases that could be involved in the increased expression of sialyl-Lewis ${ }^{\mathrm{x}}$ and 6-sulfo-sialyl-Lewis ${ }^{\mathrm{x}}$ epitopes in the bronchial mucins in inflammatory mucosae of CF patients (Figure 6).

\section{DISCUSSION}

Our study clearly demonstrates the influence of IL-6 and IL-8, two pro-inflammatory cytokines, on the expression and activity of several fucosyl-, sialyl-and sulfotransferases involved in the biosynthesis of sialyl-Le ${ }^{\mathrm{x}}$ and 6-sulfo-sialyl-Le ${ }^{\mathrm{x}}$ epitopes by the human bronchial mucosa. Several independent studies have previously shown that IL-6 and to a lower extent IL-8 can modulate protein secretion and glycosylation [23-24]. IL-6 also modulates the expression of some mucin genes by inducing an early response of MUC2, MUC5B and MUC6 mucin genes in LS180 cells [25]. In parallel, IL-8 is a chemokine that attracts neutrophils to the inflammatory sites and seems constitutively up-regulated in CF cells [26]. Its effect on glycosylation is not well documented but IL-8 has been shown to stimulate the expression of MUC5AC and MUC5B genes [27]. Considering that these two cytokines are key actors in the chronic and destructive inflammatory response exhibited by the lung of CF patients, it is therefore of particular interest to investigate the effect of these two pro-inflammatory cytokines on glycosylation process in human bronchial cells.

Our results show that the increase of sialyl-Le ${ }^{\mathrm{x}}$ and 6-sulfo-sialyl-Le $\mathrm{Le}^{\mathrm{x}}$ in cytokine treated explants is specific of a very limited number of high molecular weight proteins whereas staining with MAA or SNA reveals a broad population of $\alpha 2,3$ - and $\alpha 2,6$-sialylated glycoproteins unaffected by cytokine treatment. These results is in agreement with those of Davril et al. (1999) [14] who have shown that the amount of sialyl-Le ${ }^{\mathrm{x}}$ epitopes on high molecular weight bronchial glycoproteins depends on the severity of airway infection / inflammation and on the nature of the bacteria present in the sputum. The influence of inflammation on the biosynthesis of 6-sulfo-sialyl-Le ${ }^{\mathrm{x}}$ epitope has not been studied 
before, and it is the first time that a stimulatory effect of pro-inflammatory cytokines on that biosynthetic pathway is shown. The anti-6-sulfo-sialyl-Le ${ }^{\mathrm{x}}$ labelling showed a broad band of high molecular weight, and the immunostaining with anti-MUC mAbs strongly suggests that this epitope is carried by the membrane-bound MUC4.

Variations in the levels of expression of $M U C$ genes were observed between the bronchial samples, which is not surprising considering the different factors inducing heterogeneity in the model of human bronchial explants. Indeed, explants were obtained from patients differing in age, sex, stage of the disease and treatment before surgery, and the lung area from which the explant was obtained can also vary. It is known that the gel-forming mucin genes $(M U C 2,-5 A C,-5 B,-6)$ are regulated at the transcriptional level by pro-inflammatory cytokines such as IL-1 $\beta$, TNF $\alpha$ and IL- 6 , pleiotropic cytokines (IL-4, IL-13, IL-9), as well as by other mediators like growth factors and hormones [25, 28-29] In this study, the effect of IL- 6 and IL- 8 on $M U C 4,-5 A C$, and $5 B$ expression was investigated, but inconsistent effects of both cytokines on the expression of these genes was observed, with sometimes opposite effects from one sample to the other. This seems to indicate that the effect of cytokines on $M U C$ gene expression observed with cultured cells is not directly transposable to bronchial explants.

As it has already been reported by Delmotte and co-workers, no expression of fucosyltransferases genes FUT1, FUT5, FUT6, and FUT7 was observed in bronchial explants [20]. In addition, we found that FUT9 gene encoding an enzyme preferentially synthesizing the Le ${ }^{\mathrm{x}}$ epitope [30], is not expressed in the control or treated bronchial explants and FUT4, encoding a fucosyltransferase that preferentially synthesizes the sialyl-Le ${ }^{\mathrm{x}}$ epitope [31], was only detectable in a few samples. Interestingly, FUT10 and FUT11 genes encoding putative $\alpha 1,3 / 4$-fucosyltransferases of still unknown activities [32], are expressed in human bronchial mucosa. As already described, human bronchial explants express FUT2, encoding the secretor enzyme, and FUT3, encoding the Lewis enzyme [20]. The result of our screening on fucosyltransferase expression is in agreement with the analysis of FUT genes in mouse lung by Comelli et al. (2006) [33] using a Glycogene focused microarray approach. Quantitative PCR analysis of FUT2, 3, 10 and 11 transcripts in treated explants revealed that only FUT3 and FUT11 expression was significantly modified, after treatment with IL-8 and IL-6, respectively. The $\alpha 1,3 / 4$-fucosyltransferase FucT III is, together with FucT IV and FucT VII, involved in sialyl-Le ${ }^{\mathrm{x}}$ biosynthesis pathway and the increased expression of FUT3 could be therefore responsible for the increased synthesis of the sialyl-Le ${ }^{\mathrm{x}}$ epitope on human bronchial glycoproteins. This is in agreement with a recent report showing the increased expression of FUT3 and sialyl-Le ${ }^{\mathrm{x}}$ in TNF- $\alpha$ in the mucoepidermoid lung cancer cell line NCI-H292 [34]. It is also of particular interest that FUT11 is expressed and up-regulated by IL-6 in the human bronchial explants. The FUT11 gene encodes a Golgilocalized protein of still unknown enzymatic specificity. It has been shown that this protein does not fucosylate Galß1-4GlcNAc units, but its activity has not been tested on other substrates yet. It is 
therefore possible that FucT XI is a fucosyltransferase involved in sialyl-Le ${ }^{\mathrm{x}}$ and/or 6-sulfo-sialyl-Le biosynthesis.

The two $\alpha 2,6$-sialyltransferase genes ST6GAL1 and ST6GAL2 are expressed in human bronchial explants and respond in a different way to the addition of cytokines. The expression of ST6GAL1 was not affected by the addition of IL-6 or IL-8, whereas ST6GAL2 was strongly induced by both cytokines in all treated explants. ST6Gal I expression was previously shown to be IL-6 dependent in hepatocytes. In liver, ST6GAL1 is expressed as a $4.3 \mathrm{~kb}$ transcript under the control of a liver-specific promoter different from the promoter used in other tissues, in which $S T 6 G A L 1$ is expressed as a 4.7 $\mathrm{kb}$ transcript [35]. This tissue-specific expression of ST6GAL1 could explain the absence of induction in cytokine treated explants. Whereas ST6GAL2 was strongly induced in all cytokine treated explants, SNA labelling shows that $\alpha 2,6$-sialylation of glycoproteins is not modified in treated bronchial explants. This result could be explained by the differences in substrate specificity and expression levels of these two enzymes: ST6Gal I is an ubiquitously expressed enzyme involved in the $\alpha 2,6$-sialylation of glycans carrying type 2 disaccharide units (Galß1-4GlcNAc). ST6Gal II shows a much more restricted expression pattern and exhibits a slightly different substrate specificity [36-37], acting preferentially on LacdiNAc structures (GalNAc $\beta 1-4$ GlcNAc), a motif present on very few human glycoproteins. It is likely that the $\alpha 2,6$-linked sialic acids present in explants (and visualized by SNA staining) are carried by the classical type 2 disaccharides present mostly on $N$-glycan branches, which are a better substrate for ST6Gal I. In addition, although not induced by cytokines, the level of expression of ST6GAL1 is higher than ST6GAL2 (even in treated explants). Until now, sialyl-LacdiNAc has never been characterized in human bronchial tissue but its limited expression onto specific glycoproteins could occur and play a specific role during inflammation.

Among $\alpha 2,3$-sialyltransferases genes (ST3GAL3, 4 and 6 ) involved in the sialylation of type 2 units (the precursor of the sialyl-Le $\mathrm{x}$ epitope), only ST3GAL6 expression was significantly increased in IL-6 treated bronchial explants. This enzyme was already shown to be expressed in human and mouse lung $[33,38]$ and is therefore a good candidate for the synthesis of the sialyl-Le ${ }^{\mathrm{x}}$ epitope in this tissue.

ST3GAL3 and ST3GAL4 are both expressed in our model but their expression was not significantly affected by IL-6 or IL-8.

Human bronchial mucins were shown to contain sulfate residues, either on the $\mathrm{C} 3$ of terminal Gal residues, or on the C6 of internal GlcNAc residues [15]. In cystic fibrosis, bronchial mucins are highly sulfated, and the structures determined by $\left[{ }^{1} \mathrm{H}\right]$-NMR and MS suggest that CF bronchial mucins carry more sulfated GlcNAc residues than mucins from patients suffering from chronic bronchitis. Genes encoding Ga1-3-O-sulfotransferases active on glycoproteins showed either very low or no expression in our model, except GAL3ST4. The sulfotransferase Gal3ST4 was previously shown to be active on mucin-type structures [39]. Although Delmotte and co-workers could detect an increased Gal-3-O- 
sulfotransferase activity in TNF $\alpha$-treated bronchial explants [20], the addition of IL-6 or IL-8 did not significantly modify the expression of ST3GAL4 in a similar model.

Among genes encoding GlcNAc-6-O-sulfotransferases, we studied CHST2 and CHST4, two genes encoding enzymes able to synthesize the 6-sulfo-sialyl-Le ${ }^{\mathrm{x}}$ epitope, especially on HEV. CHST2 was not expressed in bronchial explants, whereas the expression of CHST4 was slightly increased in the presence of IL-6. The expression of CHST4 was previously shown to be induced by TNF- $\alpha$ in cultured endothelial cells [40]. It is of interest that both allergic sheep and human asthmatics exhibit airway secretions, presumably mucins that are stained by the monoclonal antibody MECA-79 [41]. MECA-79 recognizes mucin-type core-1 extended with a 6-sulfo-sialyl-Le ${ }^{\mathrm{x}}$ determinant. It seems that the major source of MECA-79-reactive glycoproteins is the airway epithelium in which CHST4 was found to be expressed. It has been proposed that the MECA-79 reactive secretions could provide extravascular ligands (adhesive or signalling) for leukocytes migrating into airways [41].

We also investigated variations in the expression of genes encoding sulfotransferases acting on glycoproteins but not preferentially involved in 6-sulfo-sialyl-Le ${ }^{x}$ biosynthesis, i.e. the gene encoding GlcNAc6ST-3 [42], and CHST6 [43] that acts preferentially on terminal GlcNAc residues of keratan sulfate chains. Enzymes encoded by these two genes have not been yet implicated in 6-sulfo-sialyl$\mathrm{Le}^{\mathrm{x}}$ biosynthesis, but they both sulfate terminal GlcNAc residues of oligosaccharide chains and are therefore potential candidates for this biosynthesis pathway. The gene encoding GlcNAc6ST3 was not expressed in both control or treated bronchial explants. CHST6 expression was induced both by IL-6 and IL-8 in the bronchial explants, although moderately concerning IL-8. Our results point at CHST4 and CHST6 as major sulfotransferase genes expressed and induced by cytokines in bronchial explants. Altogether, this study allows us to suggest which enzymes are involved in the cytokine-induced sialyl$\mathrm{Le}^{\mathrm{x}}$ and 6-sulfo-sialyl-Le ${ }^{\mathrm{x}}$ biosynthesis in the bronchial mucosa of CF patients (Figure 6).

Sialyl-Le ${ }^{\mathrm{x}}$ epitopes have been detected on mucin-type glycoproteins in different cell types and display important biological roles. Cell surface sialyl-Le ${ }^{\mathrm{x}}$ is recognized by the endothelial selectins, is involved in leukocyte homing and rolling during inflammation [44]. Sialyl-Le ${ }^{\mathrm{x}}$ is also overexpressed in many carcinomas and is usually considered as a poor prognosis factor, since the interaction of this epitope with selectins facilitates extravasation and spreading of cancer cells [45]. Interactions between macromolecules carrying abnormally expressed Sialyl-Le ${ }^{\mathrm{x}}$ and cells carrying selectins (leucocytes, endothelial cells) could modulate the inflammatory response, by competing with the relevant selectin ligands [46]. 6-sulfo-sialyl-Le ${ }^{\mathrm{x}}$ is a major sulfated L-selectin ligand present on mucin-type proteins such as CD34 and GlyCAM-1 on high endothelial venules (HEV) of lymph nodes and is essential for lymphocyte rolling and lymphocyte recruitment [47]. Our results suggest that in airway mucosa, the inflammation-induced 6-sulfo-sialyl-Le ${ }^{\mathrm{x}}$ determinant is carried by the membrane-bound bronchial mucin MUC4. Interestingly, MUC4 overexpression is a poor prognosis factor in pancreas and lung cancers, and MUC4 has been shown to be involved in pancreatic cancer progression, by modifying interactions between cancer cells and the extracellular matrix [48]. Importantly, MUC4 expression is 
negatively regulated by CFTR, the protein deficient in CF patients [49]. In the bronchial mucosa of severely infected CF patients, one could therefore expect increased levels of abnormally glycosylated MUC4 that could affect signalling and interactions. The increased expression of sialyl-Le ${ }^{\mathrm{x}}$ and $6-$ sulfo-sialyl-Le $\mathrm{e}^{\mathrm{x}}$ after cytokine treatment in human bronchial explants is therefore of important biological relevance and offers an increased number of potential ligands for leukocytes and for the binding of $P$. aeruginosa, and may therefore contribute to the chronicity of airway infection in cystic fibrosis. Moreover, the interactions of $P$. aeruginosa with mucins may prevent its opsonophagocytic killing by human polymorpho-nuclear cells [50].

Here we show which glycosyl- and sulfotransferases are up-regulated by IL-6 and IL-8 in the human bronchial mucosa, resulting in increased amounts of sialyl-Le ${ }^{\mathrm{x}}$ and 6-sulfo-sialyl-Le ${ }^{\mathrm{x}}$ epitopes on bronchial proteins, which are key determinants in the development and chronicity of the lung inflammation and infection. In the future, the study of the mechanisms by which these enzymes are regulated in the bronchial mucosa could offer new possibilities to interfere with the development of the disease in CF patients by focused approaches targeting bronchial glycosyl- and sulfotransferases by specific inhibitors or compounds that modulate their expression or activity.

\section{ACKNOWLEDGEMENTS}

We are grateful to Dr R. Kannagi (Department of Molecular Pathology, Research Institute, Aichi Cancer Center, Japan) for providing us with the anti-6-sulfo sialyl Lewis x antibody G152. We are also indebted to Dr Mensier, Dr Jaillard and Dr Mensier (Lille) for providing us with human bronchial explants. This work was supported by "Vaincre la mucoviscidose".

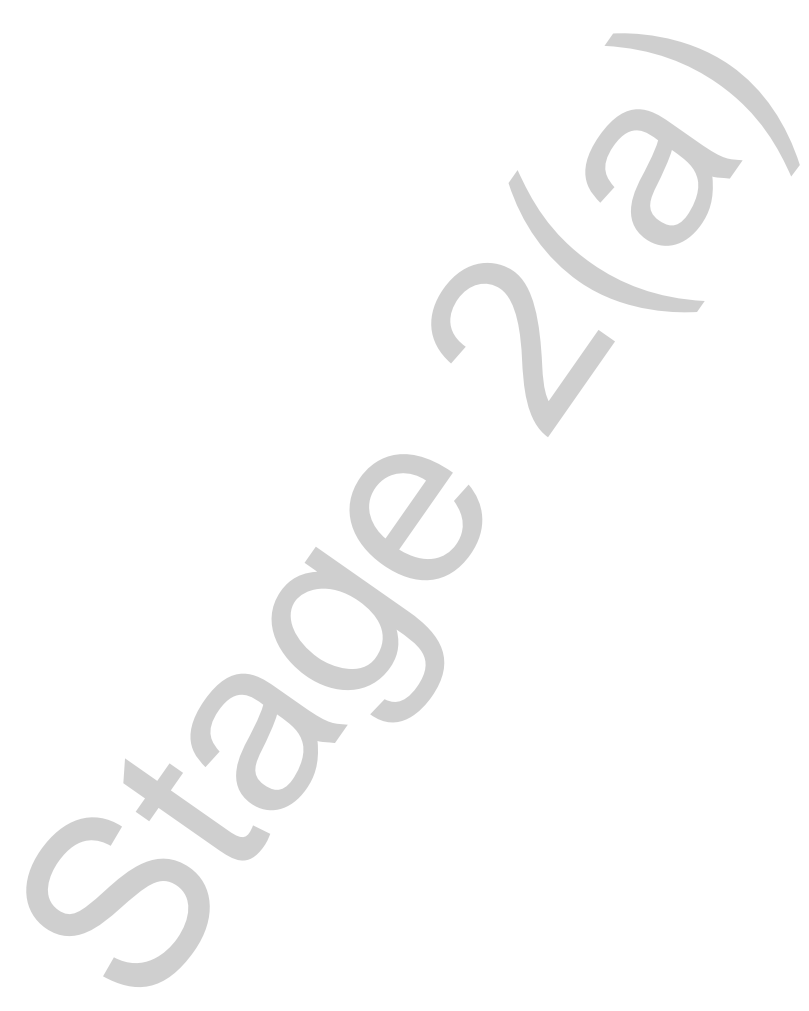




\section{References}

1. Lamblin, G., Degroote, S., Perini, J.M., Delmotte, P., Scharfman, A., Davril, M., Lo-Guidice, J.M., Houdret, N., Dumur, V., Klein, A. and Roussel, P. (2001) Human airway mucin glycosylation: a combinatory of carbohydrate determinants which vary in cystic fibrosis. Glycoconj. J., 18, 661-684.

2. Porchet, N. and Aubert, J.P. (2004) MUC genes: mucin or not mucin? That is the question (2004) Med. Sci. (Paris), 20, 569-574.

3. Roussel, P. and Lamblin, G. (2003) The glycosylation of airway mucins in cystic fibrosis and its relationship with lung infection by Pseudomonas aeruginosa. Adv. Exp. Med. Biol., 535, 17-32.

4. Degroote, S., Ducourouble, M.P., Roussel, P. and Lamblin, G. (1999) Sequential biosynthesis of sulfated and/or sialylated Lewis $\mathrm{x}$ determinants by transferases of the human bronchial mucosa. Glycobiology, 9, 1199-1211.

5. Armstrong, D.S., Grinwood, K., Caryino, R., Carlin, B., Olinsky A. and P.D. Phelan (1995) Lower respiratory infection and inflammation in infants with newly diagnosed cystic fibrosis, B.M.J., 310, 1571-1572.

6. Corvol, H., Fitting, C., Chadelat, K., Jacquot, J., Tabary, O., Boule, M., Cavaillon, J.M. and Clement, A. (2003) Distinct cytokine production by lung and blood neutrophils from children with cystic fibrosis, Am. J. Physiol. Lung Cell. Mol. Physiol., 284, L997-L1003.

7. Bonfield, T.L., Konstan, M.W. and Berger, M. J. (1999) Altered respiratory epithelial cell cytokine production in cystic fibrosis. Allergy Clin. Immunol., 104, 72-78.

8. Tabary, O., Zahm, J.M., Hinnrasky, J., Couetil, J.P., Cornillet, P., Guenounou, M., Gaillard, D., Puchelle, E. and Jacquot, J. (1998) Selective up-regulation of chemokine IL-8 expression in cystic fibrosis bronchial gland cells in vivo and in vitro. Am. J. Pathol. 153, 921-930.

9. Bonfield, T.L., Panuska, J.R., Konstan, M.W., Hilliard, K.A., Hilliard, J.B., Ghnaim, H. and Berger, M. (1995) Inflammatory cytokines in cystic fibrosis lungs. Am. J. Respir. Crit. Care Med., 152, 2111-2118.

10. Saadane, A., Soltys, J. and Berger, M. (2005) Role of IL-10 deficiency in excessive nuclear factor-kappaB activation and lung inflammation in cystic fibrosis transmembrane conductance regulator knockout mice. J. Allergy Clin. Immunol., 115, 405-411.

11. Lazatin, J., Glick, M. and Scanlin, T. (1994) Fucosylation in cystic fibrosis airway epithelial cells. Glycosylation Dis., 1, 263-270.

12. Lamblin, G., Lhermitte, M., Lafitte, J.J., Filliat, M., Degand, P. and Roussel, P. (1977) Comparative study of bronchial mucins isolated from the sputum of patients suffering from cystic fibrosis or other chronic bronchial diseases. Bull. Eur. Physiopathol. Respir., 13, 175-190. 
13. Carnoy, C., Ramphal, R., Scharfman, A., Lo-Guidice, J.M., Houdret, N., Klein, A., Galabert, C., Lamblin, G. and Roussel, P. (1993) Altered carbohydrate composition of salivary mucins from patients with cystic fibrosis and the adhesion of Pseudomonas aeruginosa. Am. J. Respir. Cell. Mol. Biol. 9, 323-334.

14. Davril, M., Degroote, S., Humbert, P., Galabert, C., Dumur,V., Lafitte, J.J., Lamblin, G. and Roussel, P. (1999) The sialylation of bronchial mucins secreted by patients suffering from cystic fibrosis or from chronic bronchitis is related to the severity of airway infection. Glycobiology, 9 , 311-321.

15. Lo-Guidice, J.M., Wieruszeski, J.M., Lemoine, J., Verbert, A., Roussel, P. and Lamblin, G. (1994) Sialylation and sulfation of the carbohydrate chains in respiratory mucins from a patient with cystic fibrosis. J. Biol. Chem., 269, 18794-18813.

16. Leir, S.H., Parry, S., Palmai-Pallag, T., Evans, J., Morris, H.R., Dell, A. and Harris, A. (2005) Mucin glycosylation and sulphation in airway epithelial cells is not influenced by cystic fibrosis transmembrane conductance regulator expression. Am. J Respir. Cell. Mol. Biol., 32, 453-461.

17. Jiang, X., Hill, W.G., Pilewski, J.M. and Weisz, O.A. (1997) Glycosylation differences between a cystic fibrosis and rescued airway cell line are not CFTR dependent. Am. J. Physiol., 273, L913920

18. Rhim, A.D., Kothari, V.A., Park, P.J., Mulberg, A.E., Glick, M.C. and Scanlin, T.F. (2000) Terminal glycosylation of cystic fibrosis airway epithelial cells. Glycoconj. J., 17, 385-391.

19. Scharfman, A., Delmotte, P., Beau, J., Lamblin, G., Roussel, P. and Mazurier, J. (2000) Sialyl$\mathrm{Le}(\mathrm{x})$ and sulfo-sialyl-Le(x) determinants are receptors for P. aeruginosa. Glycoconj J., 17, 735 740 .

20. Delmotte, P., Degroote, S., Lafitte, J.J., Lamblin, G., Perini, J.M. and Roussel, P. (2002) Tumor necrosis factor alpha increases the expression of glycosyltransferases and sulfotransferases responsible for the biosynthesis of sialylated and/or sulfated Lewis x epitopes in the human bronchial mucosa. J. Biol. Chem., 277, 424-431.

21. Mitsuoka, C., Sawada-Kasugai, M., Ando-Furui, K., Izawa, M., Nakanishi, H., Nakamura, S., Ishida, H., Kiso, M. and Kannagi, R. (1998) Identification of a major carbohydrate capping group of the L-selectin ligand on high endothelial venules in human lymph nodes as 6-sulfo sialyl Lewis X. J Biol Chem.; 273, 11225-11233.

22. Piessen, G., Jonckheere, N., Vincent, A., Hémon, B., Ducourouble, M.P., Copin, M.C., Mariette, C. and Van Seuningen, I. (2007) Regulation of the human mucin MUC4 by taurodeoxycholic and taurochenodeoxycholic bile acids in oesophageal cancer cells is mediated by hepatocyte nuclear factor 1alpha. Biochem. J., 402, 81-91 
23. Azuma, Y., Murata, M. and Matsumoto, K. (2000) Alteration of sugar chains on $\alpha 1$-acid glycoprotein secreted following cytokine stimulation of HuH-7 cells in vitro. Clin. Chim. Acta, 294, 93-103.

24. Dalziel, M., Lemaire, S., Ewing, J., Kobayashi, L. and Lau, J.T. (1999) Hepatic acute phase induction of murine $\beta$-galactoside $\alpha 2,6$-sialyltransferase (ST6Gal I) is IL-6 dependent and mediated by elevation of exon H-containing class of transcripts. Glycobiology, 9, 1003-1008.

25. Enss, ML., Cornberg, M., Wagner, S., Gebert, A., Henrichs, M., Eisenblätter, R., Beil, W., Kownatzki, R. and Hedrich, H.J. (2000) Proinflammatory cytokines trigger MUC gene expression and mucin release in the intestinal cancer cell line LS180. Inflamm. Res., 49, 162-169.

26. Kammouni, W., Figarella, C., Marchand, S. and Merten, M. (1997) Altered cytokine production by cystic fibrosis tracheal gland serous cells. Infect. Immun. 65, 5176-5183.

27. Smirnova, M.G., Birchall, J.P. and Pearson, J.P. (2002) In vitro study of IL-8 and goblet cells: possible role of IL-8 in the aetiology of otitis media with effusion. Acta Otolaryngol., 122, 146152.

28. Van Seuningen, I., Pigny, P., Perrais, M., Porchet, N. and Aubert, J.P. (2001) Transcriptional regulation of the 11 p15 mucin genes. Towards new biological tools in human therapy, in inflammatory diseases and cancer? Front. Biosci., 6, D1216-D1234.

29. Smirnova, M.G., Kiselev, S.L., Birchall, J.P., Pearson, J.P. (2001) Up-regulation of mucin secretion in HT29-MTX cells by the pro-inflammatory cytokines tumor necrosis factor-alpha and interleukin-6. Eur. Cytokine Netw., 12, 119-125.

30. Nishihara, S., Iwasaki, H., Kaneko, M., Tawada, A., Ito, M. and Narimatsu, H. (1999) a1,3fucosyltransferase 9 (FUT9; Fuc-TIX) preferentially fucosylates the distal GlcNAc residue of polylactosamine chain while the other four $\alpha 1,3 \mathrm{FUT}$ members preferentially fucosylate the inner GlcNAc residue. FEBS Lett., 462, 289-294.

31. Easton, E.W., Schiphorst, W.E,, van Drunen, E., van der Schoot C.E. and van den Eijnden, D.H. (1993) Human myeloid $\alpha 3$-fucosyltransferase is involved in the expression of the sialyl-Lewis(x) determinant, a ligand for E- and P-selectin. Blood., 81, 2978-2986.

32. Baboval, T, and Smith, F.I. (2002) Comparison of human and mouse Fuc-TX and Fuc-TXI genes, and expression studies in the mouse. Mamm. Genome, 13, 538-541.

33. Comelli, E.M., Head, S.R., Gilmartin, T., Whisenant, T., Haslam, S.M., North, S.J., Wong, N.K., Kudo, T., Narimatsu, H., Esko, J.D., Drickamer, K., Dell, A. and Paulson, J.C. (2006) A focused microarray approach to functional glycomics: transcriptional regulation of the glycome.

Glycobiology, 16, 117-131.

34. Ishibashi, Y., Inouye, Y., Okano, T. and Taniguchi, A. (2005) Regulation of sialyl-Lewis x epitope expression by TNF-alpha and EGF in an airway carcinoma cell line.Glycoconj J., 22, 53-62. 
35. Svensson, E.C., Conley, P.B. and Paulson, J.C. (1992) Regulated expression of alpha 2,6sialyltransferase by the liver-enriched transcription factors HNF-1, DBP, and LAP. J. Biol. Chem., 267, 3466-3472.

36. Krzewinski-Recchi, M.A., Julien, S., Juliant, S., Teintenier-Lelievre, M., Samyn-Petit, B., Montiel, M.D., Mir, A.M., Cerutti, M., Harduin-Lepers, A. and Delannoy, P. (2003) Identification and functional expression of a second human $\beta$-galactoside $\alpha 2,6$-sialyltransferase, ST6Gal II. Eur. J. Biochem. 270, 950-961.

37. Rohfritsch, P.F., Joosten, J.A., Krzewinski-Recchi, M.A., Harduin-Lepers, A., Laporte, B., Juliant, S., Cerutti, M., Delannoy, P., Vliegenthart, J.F. and Kamerling, JP. (2006) Probing the substrate specificity of four different sialyltransferases using synthetic $\beta$-D-Galp-(1-4)- $\beta$-D-GlcpNAc(1-2)- $\alpha$-D-Manp-(1-O)- $\left(\mathrm{CH}_{2}\right)_{7} \mathrm{CH}_{3}$ analogues general activating effect of replacing Nacetylglucosamine by N-propionylglucosamine. Biochim. Biophys. Acta. 1760, 685-692.

38. Okajima, T., Fukumoto, S., Miyazaki, H., Ishida, H., Kiso, M., Furukawa, K., Urano, T. and Furukawa, K. (1999) Molecular cloning of a novel alpha2,3-sialyltransferase (ST3Gal VI) that sialylates type II lactosamine structures on glycoproteins and glycolipids. J. Biol. Chem. 274, 1147911486.

39. Chandrasekaran, E.V., Lakhaman, S.S., Chawda, R., Piskorz, C.F., Neelamegham, S. and Matta, KL. (2004) Identification of physiologically relevant substrates for cloned Gal: 3-O-

sulfotransferases (Gal3STs): distinct high affinity of Gal3ST-2 and LS180 sulfotransferase for the globo H backbone, Gal3ST-3 for N-glycan multiterminal Gal $\beta 1,4$ GlcNAc $\beta$ units and 6sulfoGal $\beta 1,4 \mathrm{GlcNAc} \beta$, and Gal3ST-4 for the mucin core-2 trisaccharide. J. Biol. Chem., 279, 10032-10041.

40. Pablos, J.L., Santiago, B., Tsay, D., Singer, M.S., Palao, G., Galindo, M. and Rosen, S.D. (2005) A HEV-restricted sulfotransferase is expressed in rheumatoid arthritis synovium and is induced by lymphotoxin-alpha/beta and TNF-alpha in cultured endothelial cells. BMC Immunol., 6, 1-9.

41. Rosen, S.D., Tsay, D., Singer, M.S., Hemmerich, S. and Abraham, W.M. (2005) Therapeutic targeting of endothelial ligands for L-selectin (PNAd) in a sheep model of asthma. Am. J. Pathol., 166, $935-944$.

42. Lee, J.K., Bistrup, A., van Zante, A. and Rosen, S.D. (2003) Activities and expression pattern of the carbohydrate sulfotransferase GlcNAc6ST-3 (I-GlcNAc6ST): functional implications. Glycobiology, 13, 245-254.

43. Akama, T.O., Nishida, K., Nakayama, J., Watanabe, H., Ozaki, K., Nakamura, T., Dota, A., Kawasaki, S., Inoue, Y., Maeda, N., Yamamoto, S., Fujiwara, T., Thonar, E.J., Shimomura, Y., Kinoshita, S., Tanigami, A. and Fukuda, M.N. (2000) Macular corneal dystrophy type I and type II are caused by distinct mutations in a new sulphotransferase gene. Nat Genet., 26, 237-241. 
44. Foxall, C., Watson, S.R., Dowbenko, D., Fennie,C., Lasky, L.A., Kiso, M. Hasegawa, A., Asa, D., and Brandley, B.K. (1992) The three members of the selectin receptor family recognize a common carbohydrate epitope, the sialyl Lewis(x) oligosaccharide. J. Cell. Biol.,117, 895-902.

45. Numahata, K., Satoh, M., Handa, K., Saito, S., Ohyama, C., Ito, A., Takahashi, T., Hoshi, S., Orikasa, S. and Hakomori, S.I. (2002) Sialosyl-Le(x) expression defines invasive and metastatic properties of bladder carcinoma. Cancer, 94, 673-685.

46. Crottet, P., Kim, Y.J. and Varki, A. (1996) Subsets of sialylated, sulfated mucins of diverse origins are recognized by L-selectin. Lack of evidence for unique oligosaccharide sequences mediating binding. Glycobiology, 6, 191-208.

47. Hemmerich, S., Butcher, E.C. and Rosen, S.D. (1994) Sulfation-dependent recognition of high endothelial venules (HEV)-ligands by L-selectin and MECA 79, and adhesion-blocking monoclonal antibody. J. Exp. Med., 180, 2219-2226.

48. Chaturvedi, P., Singh, A.P., Moniaux, N., Senapati, S., Chakraborty, S., Meza, J.L. and Batra, S.K. (2007) MUC4 mucin potentiates pancreatic tumor cell proliferation, survival, and invasive properties and interferes with its interaction to extracellular matrix proteins. Mol. Cancer Res., 5, 309-320.

49. Singh, A.P., Chauhan, S.C., Andrianifahanana, M., Moniaux, N., Meza, J.L., Copin, M.C., van Seuningen, I., Hollingsworth, M.A., Aubert, J.P. and Batra, S.K. (2007) MUC4 expression is regulated by cystic fibrosis transmembrane conductance regulator in pancreatic adenocarcinoma cells via transcriptional and post-translational mechanisms. Oncogene, 26, 30-41.

50. Vishwanath, S., Ramphal, R., Guay, C.M., DesJardins, D. and Pier, G.B. (1988) Respiratorymucin inhibition of the opsonophagocytic killing of Pseudomonas aeruginosa. Infect Immun., 56, 2218-2222. 


\section{LEGENDS TO FIGURES}

Figure 1: Lectin blot analysis of total proteins from human bronchial explants treated or not with IL-6 or IL-8 (20 ng· $\left.\mathrm{ml}^{-1}, 16 \mathrm{~h}\right)$.

Total proteins from control or stimulated explants were resolved by SDS-PAGE using 3-10\% gels, transferred on nitrocellulose. $\alpha 2,3-$ linked and $\alpha 2,6$-linked sialic acids were detected by MAA and SNA, respectively.

Figure 2: Immunoblot analysis of sialyl-Lewis ${ }^{\mathrm{x}}$ and 6-sulfo-sialyl-Lewis ${ }^{\mathrm{x}}$ expression in total proteins from human bronchial explants treated or not with IL-6 or IL-8 $\left(20 \mathrm{ng} \cdot \mathrm{ml}^{-1}, 16 \mathrm{~h}\right)$.

Total proteins from control or stimulated explants were resolved by SDS-PAGE using 3-10 \% gels, transferred on nitrocellulose, and sialyl-Lewis ${ }^{\mathrm{x}}$ and 6-sulfo-sialyl-Lewis ${ }^{\mathrm{x}}$ were detected using antisialyl-Lewis ${ }^{\mathrm{x}}$ CSLEX1 (A) and anti-6-sulfo-sialyl-Lewis ${ }^{\mathrm{x}}$ G152 mAbs (B), respectively.

Figure 3: Expression of $M U C 4,5 A C$ and $5 B$ mRNA in control human bronchial explants (n=8). The expression of $M U C$ genes was investigated by quantitative $\mathrm{PCR}$ and normalized to the expression of $R P L P 0$, which allows a direct comparison of expression level in the different samples. The horizontal bar represents the mean value.

Figure 4: Immunoblot analysis of 6-sulfo-sialyl-Lewis and MUC4 expression in total proteins from human bronchial explants treated or not with IL-6 or IL-8 $\left(20 \mathrm{ng} \cdot \mathrm{ml}^{-1}, 16 \mathrm{~h}\right)$.

Total proteins from control or stimulated explants were resolved by SDS-PAGE using 3-10 \% gels. 6sulfo-sialyl-Lewis ${ }^{\mathrm{x}}$ and MUC4 were detected using anti-sialyl-Lewis ${ }^{\mathrm{x}}$ G152 or anti-MUC4 m8G7 mAbs, respectively.

Figure 5: Effect of IL-6 and IL-8 $\left(20 \mathrm{ng} \cdot \mathrm{ml}^{-1}, 16 \mathrm{~h}\right)$ treatment on the relative expression of fucosyl- (FUT2, 3, 10 and 11), sialyl- (ST3GAL3, 4 and 6, ST6GAL1 and 2) and sulfotransferases (GAL3ST4, CHST4 and CHSTO) in human bronchial explants.

Variations in the relative expression of glycosyl- and sulfotransferases were determined by quantitative PCR as described in experimental procedures. Six different explants were used for each condition (open bars), the right grey bar corresponding to the mean value.

Figure 6: Glycosyl-and sulfotransferases that are up-regulated by the addition of IL-6 or IL-8, potentially involved in the increased expression of sialyl-Lewis ${ }^{\mathrm{x}}$ and 6-sulfo-sialyl-Lewis ${ }^{\mathrm{x}}$ epitopes in the bronchial mucins of CF patients.

$\beta 4$ GalT, UDP-Gal: GlcNAc $\beta 1$,4-galactosyltransferase; CHST, $N$-acetylglucosaminyl-6-Osulfotransferase; $\alpha 3$ FucT, $\alpha 1,3$-fucosyltransferase; ST3Gal, $\alpha 2,3$-sialyltransferase 
Groux-Degroote et al., Figure 1
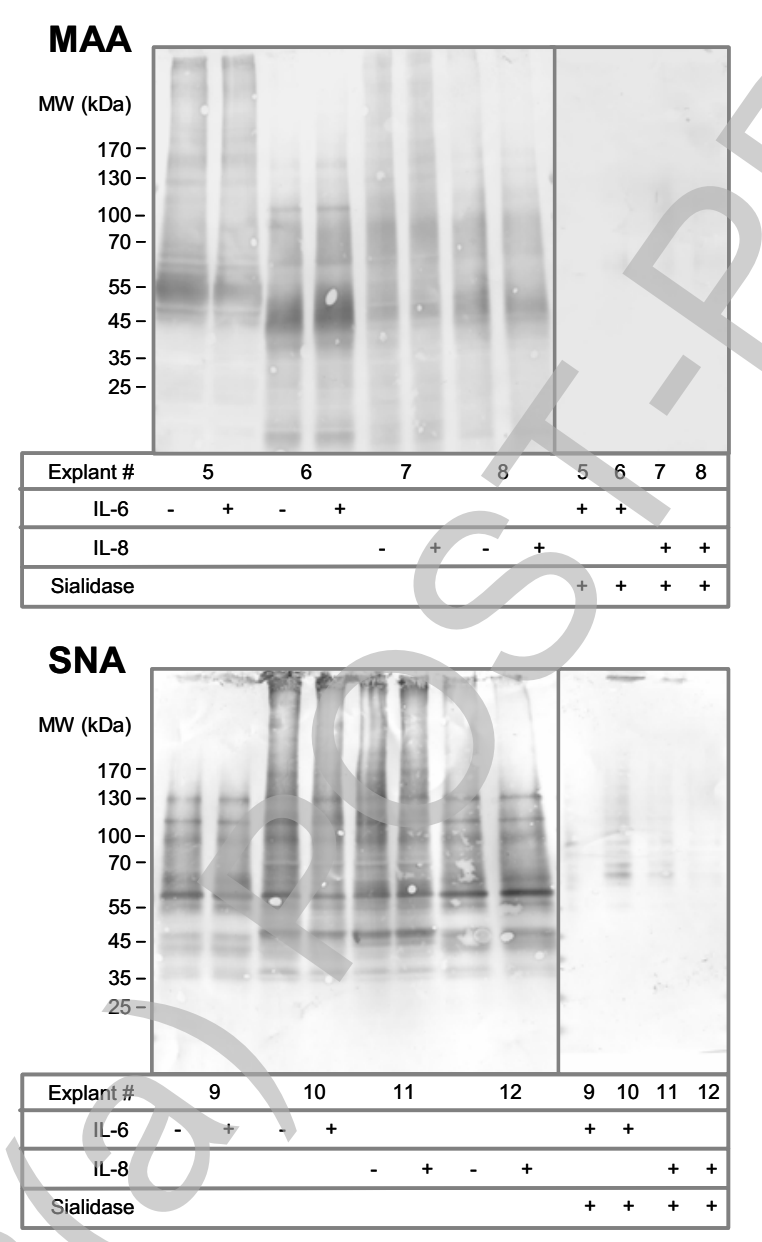

Licenced copy. Copying is not permitted, except with prior permission and as allowed by law. (C) 2007 The Authors Journal compilation (C) 2007 Biochemical Society 
Groux-Degroote et al., Figure 2
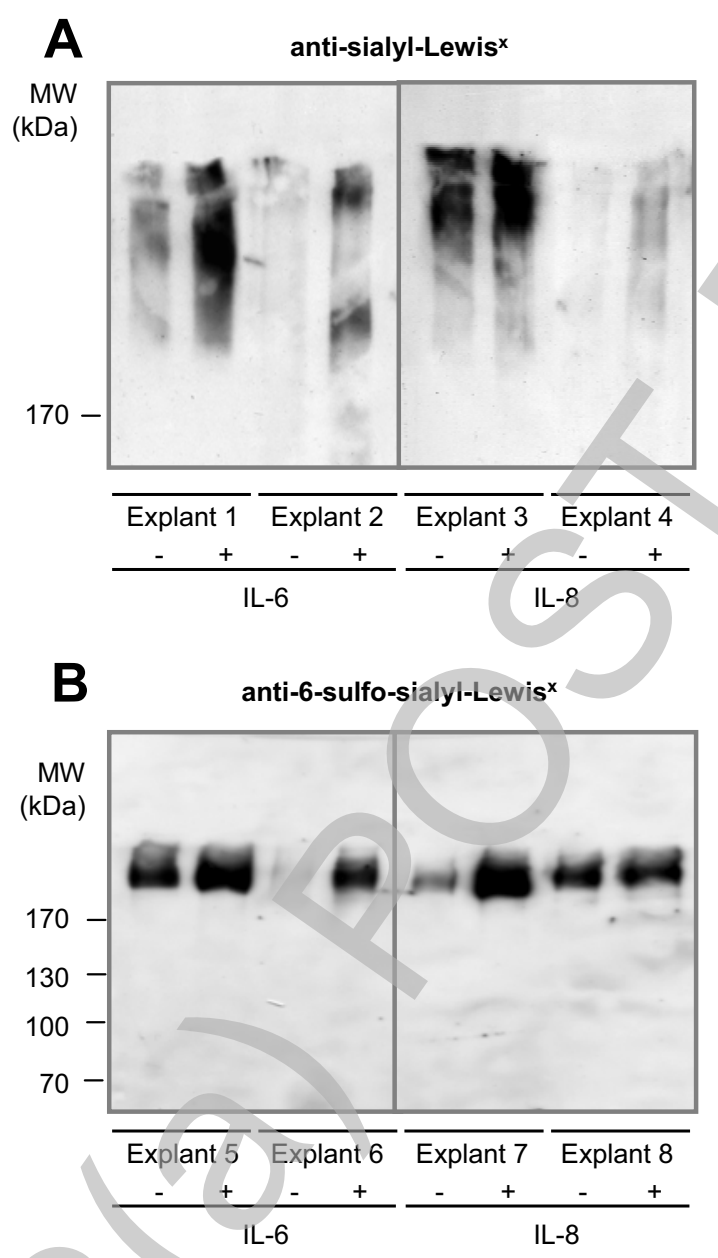

Licenced copy. Copying is not permitted, except with prior permission and as allowed by law. (C) 2007 The Authors Journal compilation (c) 2007 Biochemical Society 
Groux-Degroote et al., Figure 3

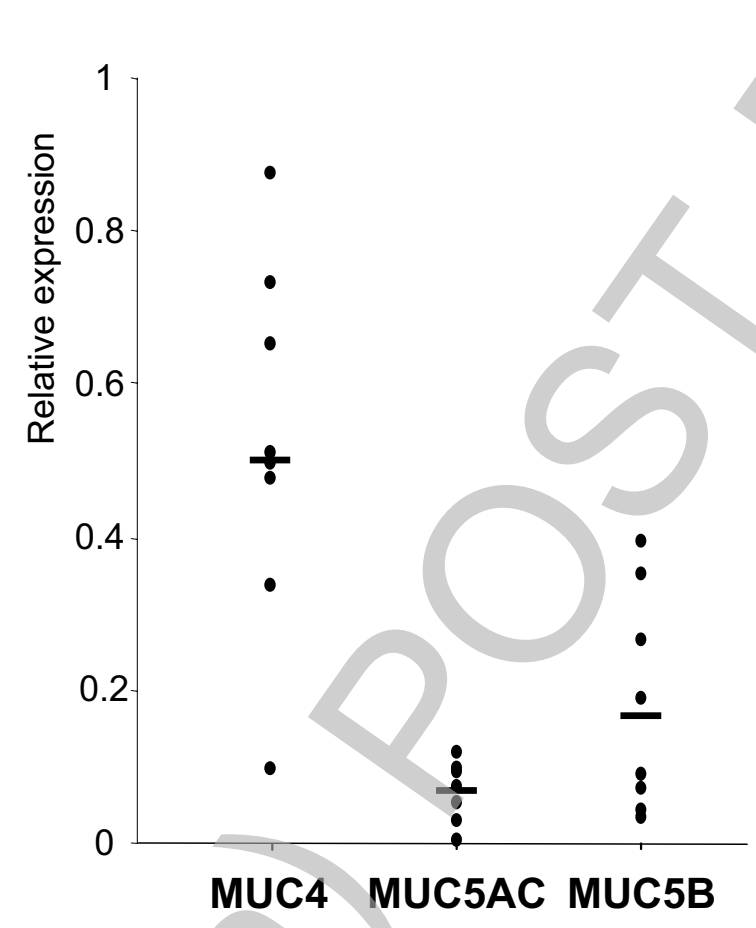

Licenced copy. Copying is not permitted, except with prior permission and as allowed by law. (c) 2007 The Authors Journal compilation (c) 2007 Biochemical Society 
Groux-Degroote et al., Figure 4

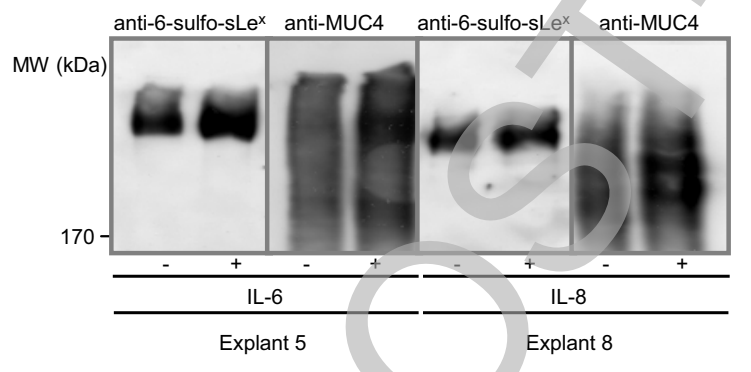

Licenced copy. Copying is not permitted, except with prior permission and as allowed by law. (C) 2007 The Authors Journal compilation (c) 2007 Biochemical Society 
Biochemical Journal Immediate Publication. Published on 18 Oct 2007 as manuscript BJ20070958

Groux-Degroote et al., Figure 5A

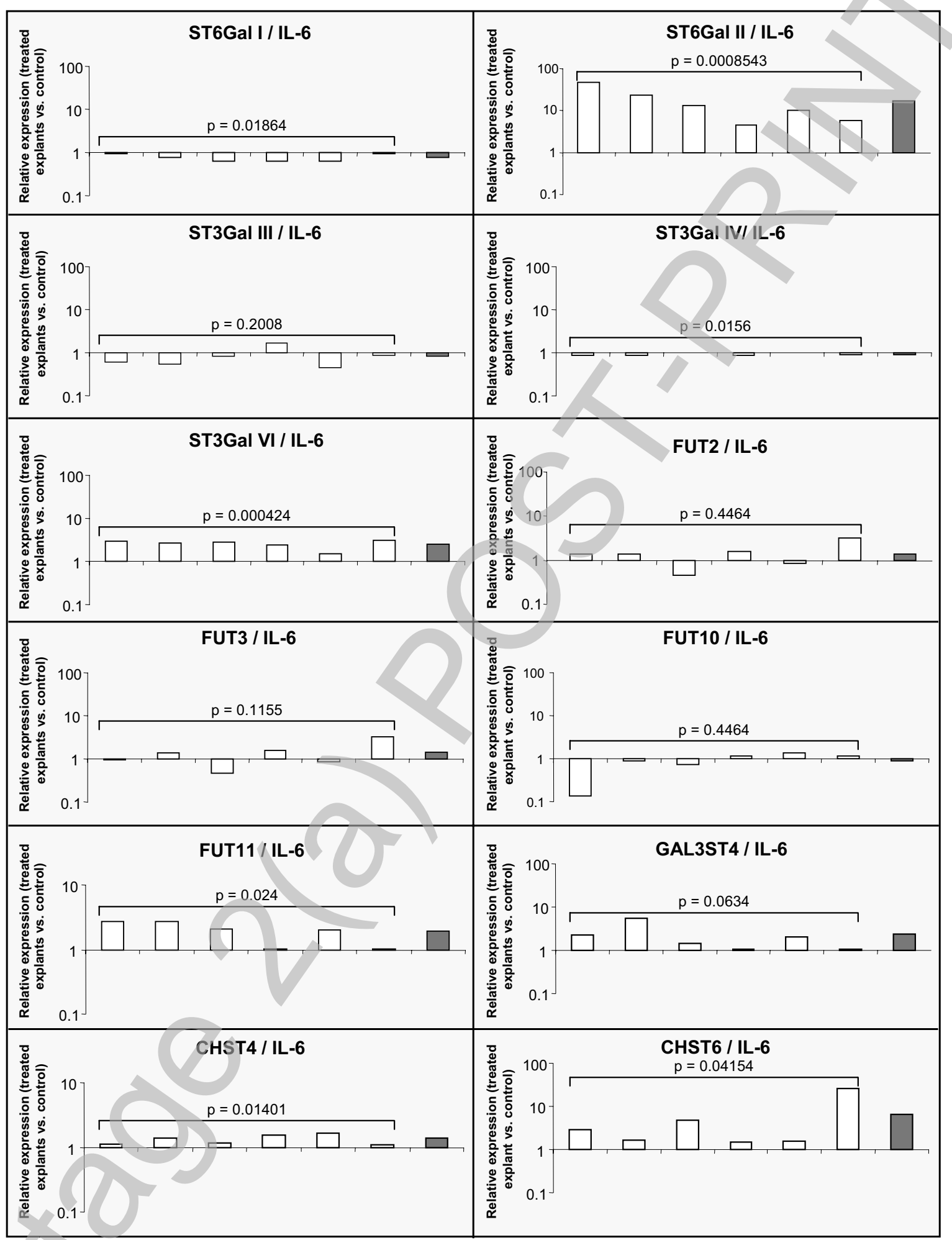

Licenced copy. Copying is not permitted, except with prior permission and as allowed by law. (C) 2007 The Authors Journal compilation (C) 2007 Biochemical Society 
Biochemical Journal Immediate Publication. Published on 18 Oct 2007 as manuscript BJ20070958

Groux-Degroote et al., Figure 5B

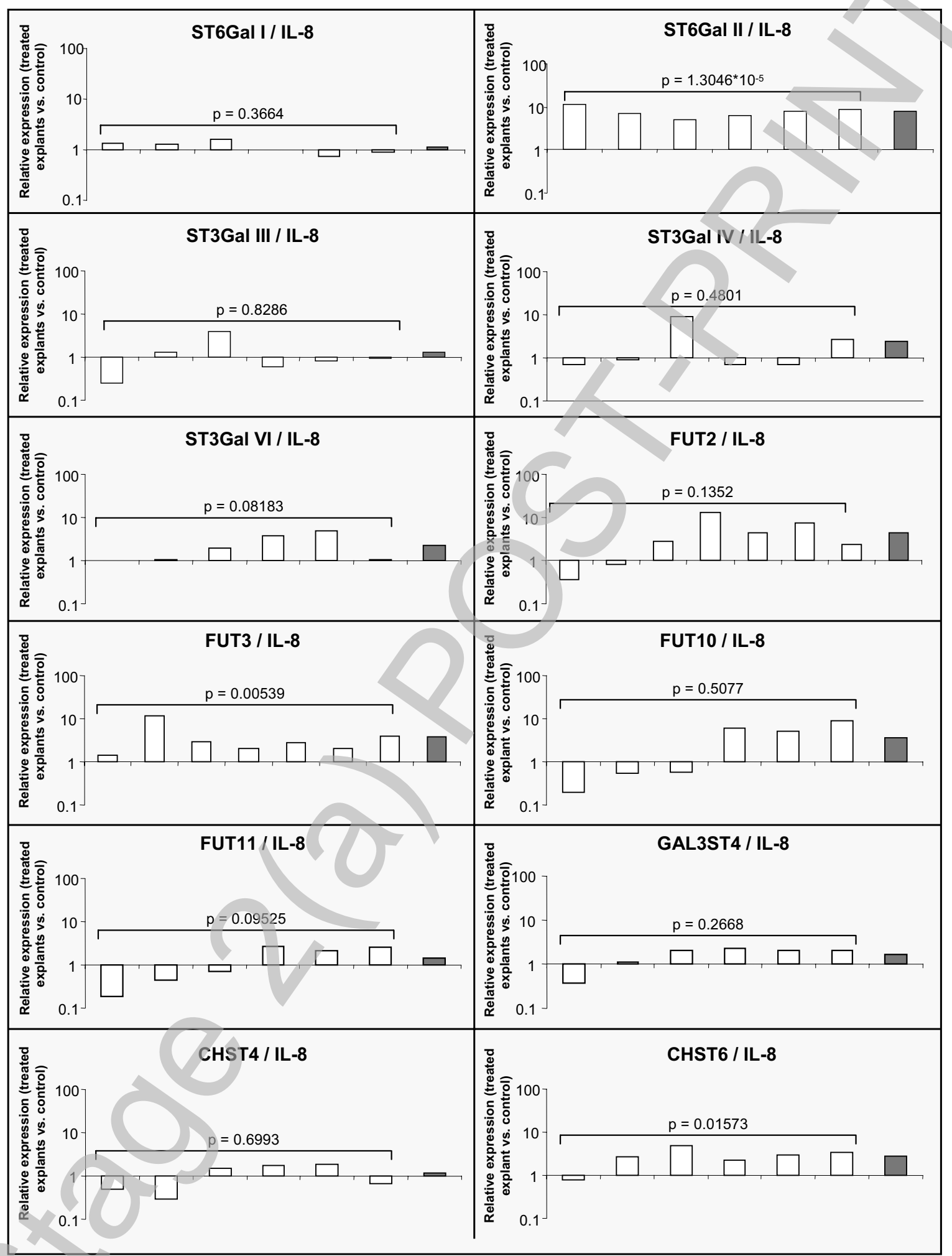

Licenced copy. Copying is not permitted, except with prior permission and as allowed by law. (C) 2007 The Authors Journal compilation (C) 2007 Biochemical Society 
Groux-Degroote et al., Figure 6

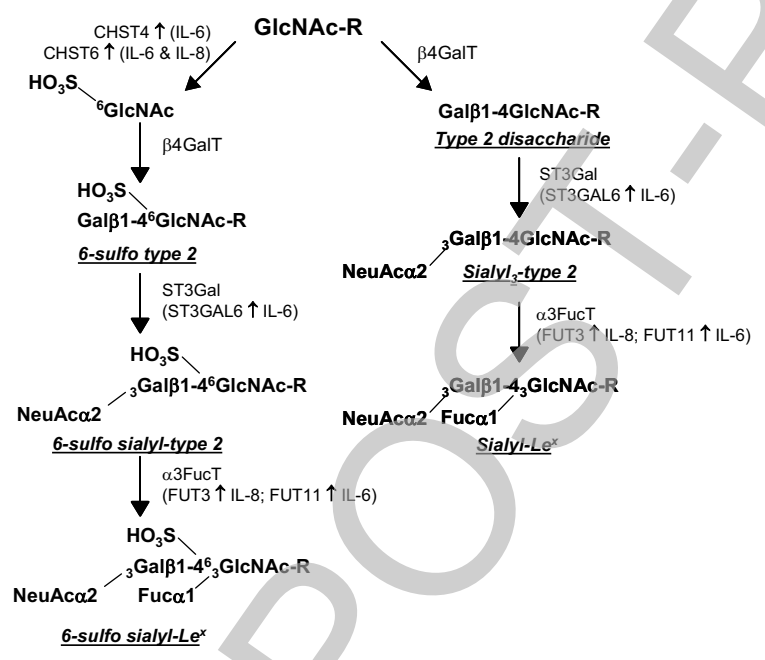

Licenced copy. Copying is not permitted, except with prior permission and as allowed by law. (C) 2007 The Authors Journal compilation (c) 2007 Biochemical Society 